\title{
O NÚCLEO DE ENSINO DA UNESP: FORMAÇÃO DOS LICENCIANDOS PARA A INCLUSÃO
}

Danielle Aparecida do Nascimento dos Santos ${ }^{1}$, Ana Mayra Samuel da Silva, Ana Virginia Isiano Lima $^{2}$, Denner Dias Barros ${ }^{3}$, Elisa Tomoe Moriya Schlünzen².

'Universidade do Oeste Paulista - UNOESTE, Programa de Pós-Graduação em Educação, Presidente Prudente, SP. ${ }^{2}$ Universidade Estadual Paulista - UNESP, Programa de Pós-Graduação em Educação, Presidente Prudente, SP. ${ }^{3}$ Universidade Estadual Paulista - UNESP, Programa de Pós-Graduação em Educação Matemática, Rio Claro, SP. E-mail: danisantos.unesp@gmail.com, ana.mayra.ss@gmail.com, anaisianolima@gmail.com, elisa@fct.unesp.br, dennerdias12@gmail.com.

Agência de fomento: Programa Núcleo de Ensino - Prograd/UNESP

\section{RESUMO}

O grupo de pesquisa Ambientes Potencializadores para a Inclusão (API), que atua no âmbito do Centro de Promoção para a Inclusão Digital, Escolar e Social (CPIDES) realiza atividades de pesquisa, extensão e formação inicial que visam promover a inclusão dos Estudantes Público-alvo da Educação Especial (EPAEE). O objetivo deste artigo é retratar o trabalho desenvolvido em um projeto proposto pela Pró-Reitoria de Graduação da Unesp, Programa Núcleo de Ensino. O projeto realizado pelos pesquisadores do API no programa, visa oportunizar aos estudantes de cursos de licenciatura da Faculdade de Ciências e Tecnologia - FCT/Unesp um contato com os EPAEE e a vivência em uma realidade escolar, acompanhando a inclusão nas instituições de ensino. 0 programa tem oportunizado discussões sobre educação inclusiva durante a formação inicial de professores.

Palavras-chave: Ambientes Potencializadores para a Inclusão, Núcleo de Ensino, Estudantes Público-Alvo da Educação Especial, Educação Inclusiva.

\section{THE UNESP EDUCATION CORE: LICENSING TRAINING FOR INCLUSION}

\begin{abstract}
The research group improvers Environments for Inclusion, which operates under the Promotion Center for Digital Inclusion, School and Social conducts research, initial extension and training to promote the inclusion of Public- Students target of Special Education. The purpose of this article is to portray the work on a project proposed by the Dean of Graduate Unesp, Education Center Program. The project carried out by researchers in API program aims to create opportunities for students to degree courses of the Faculty of Science and Technology - FCT/Unesp contact with the EPAEE and living in a school reality, following the inclusion in educational institutions. The program has potentiated discussions on inclusive education during the initial training of teachers.

Keywords: Improvers environments for Inclusion, Education Center, Target audience Students of Special Education, Inclusive Education.
\end{abstract}




\section{INTRODUÇÃO}

As instituições educacionais em nosso país destinaram, durante muitos anos, a escolarização à apenas um grupo, relevando uma exclusão legitimada a muitos estudantes, principalmente àqueles que possuíam algum tipo de deficiência. Em âmbito nacional, após a promulgação de documentos legais que buscavam o acesso de mais estudantes à escola, a Constituição Federal Brasileira de 1988 consagra a educação como um direito de todos. Além disso, estabelece igualdade das condições de acesso e permanência nas instituições escolares, assim como a Lei de Diretrizes e Bases para Educação Nacional (LDBEN) de 1996.

Diante disso, ao se considerar a necessidade de se constituírem nas escolas, espaços inclusivos, outros documentos legais que norteiam a constituição da Educação Especial e Inclusiva estão em vigor em nosso país, como: a Declaração Mundial sobre Educação para Todos (1990), instituída em Jomtiem, a Declaração de Salamanca (1994), as Diretrizes Nacionais para a Educação Especial na Educação Básica (2001), e a Política Nacional de Educação Especial na Perspectiva da Educação Inclusiva (2008).

Além de estabelecerem a educação como um direito de todos, tais documentos legais afirmam que as instituições de ensino devem criar mecanismos que atendam as diferentes especificidades dos estudantes, buscando o desenvolvimento pleno de cada um em suas dimensões sociais, morais, afetivas, políticas, físicas, entre outras.

Nessa perspectiva, considerando as políticas vigentes, o grande desafio inerente ao cenário educacional brasileiro é constituir escolas que reconheçam, valorizem as diferenças e ofereçam um ensino de qualidade. Conforme Mantoan (2008), as instituições de ensino que atuam na construção de escolas inclusivas se especializam em todos os estudantes, assumindo suas dificuldades e potencialidades para que reflitam em como a aprendizagem é concebida e avaliada.

Diante dessas premissas, o grupo de pesquisa Ambientes Potencializadores para Inclusão (API) tem se comprometido com o desenvolvimento de atividades de ensino, pesquisa e extensão, bem como de formação inicial de professores, com o intuito auxiliar, em uma perspectiva colaborativa, as unidades escolares para que a inclusão se efetive.

No âmbito do Centro de Promoção para a Inclusão Digital, Escolar e Social (CPIDES), localizado na Faculdade de Ciências e Tecnologia (FCT-UNESP), é realizado um projeto, vinculado ao Programa Núcleo de Ensino (NE) da Unesp, um programa de responsabilidade da Pró-Reitoria de Graduação (Prograd), que tem por objetivo trabalhar com os cursos de graduação no desenvolvimento de práticas educacionais nas escolas de Educação Infantil, Ensino Fundamental e Ensino Médio, almejando melhoria na qualidade do ensino oferecido pelas instituições.

O projeto desenvolvido pelo grupo API, em parceria com o programa, teve início no ano de 2006 com o intuito de elaborar estratégias pedagógicas inclusivas que contribuam para a construção de ambientes educacionais condizentes com a abordagem Construcionista, Contextualizada e Significativa (CCS), oportunizando a inclusão dos Estudantes Público-Alvo da Educação Especial (EPAEE) a partir do uso de tecnologias.

A abordagem CCS, definida por Schlünzen (2000), articula os conceitos com o currículo, contextualizando-os e atribuindo significado a eles. De acordo com a autora,

[...] o ambiente Construcionista, Contextualizado e Significativo é um ambiente favorável que desperta o interesse do aluno e o motiva a explorar, a pesquisar, a descrever, a refletir a depurar as suas ideias. É aquele cujo problema nasce de um movimento na sala de aula, no qual os alunos, junto com o professor, decidem desenvolver, com auxílio do computador, um projeto que faz parte da vivência e do contexto dos alunos. No desenvolvimento deste projeto, os alunos irão se deparando com os conceitos das disciplinas curriculares e o 
professor mediará a sua formalização para que o aluno consiga dar significado ao que está sendo aprendido. (SCHLÜNZEN, 2000, p. 82).

Considerando a necessidade de desenvolver esse ambiente CCS no contexto da escola, proporcionando ao licenciando a vivência dessa realidade, neste artigo, apresentaremos os resultados que alcançamos desde 2006, especialmente no que se refere à qualidade da formação inicial e continuada de professores, e ao esclarecimento dos licenciandos e dos professores em relação à abordagem CCS e à inclusão escolar.

\section{METODOLOGIA}

A abordagem para o desenvolvimento da pesquisa é a qualitativa. De acordo com Richardson (2012, p. 80),

[...] os estudos que empregam uma metodologia qualitativa podem descrever a complexidade de determinado problema, analisar a interação de certas variáveis, compreender e classificar processos dinâmicos vividos por grupos sociais, contribuir no processo de mudança de determinado grupo e possibilitar, em maior nível de profundidade, o entendimento das particularidades do comportamento dos indivíduos. (RICHARDSON, 2012, p. 80)

O grupo de pesquisa Ambientes Potencializadores para Inclusão (API), se submeteu ao Comitê de Ética em Pesquisa (CEP), sendo o número CAAE: 10206912.2.0000.5402. Diante da aprovação do comitê, os autores deste artigo, participantes do grupo de pesquisa API, possuem autorização para a divulgação dos dados do projeto Núcleo de Ensino.

Considerando os objetivos do projeto, voltados a construir espaços inclusivos a partir da abordagem CCS, a equipe que realiza os estudos é formada por estudantes de graduação da FCT/Unesp e por pesquisadores do grupo API. Para iniciarmos as atividades relacionadas com o projeto, anualmente a equipe responsável realiza contato com as secretarias estaduais e municipais de educação, visando estabelecer a parceria para o desenvolvimento das atividades. Em 2016, o projeto possui escolas parceiras nos municípios de Araçatuba/SP e Presidente Prudente/SP.

A partir do contato com as instituições de ensino, os pesquisadores e estagiários iniciam um diagnóstico da escola, realizando observações não participantes para analisar como ocorre a inclusão dos EPAEE no ambiente escolar. Diante disso, inicia-se a elaboração e planejamento das estratégias pedagógicas a serem desenvolvidas nas instituições de ensino com os participantes da pesquisa, segundo as concepções da abordagem CCS.

No desenvolvimento das atividades, os estudantes bolsistas que participam do projeto vivenciam o contexto escolar, observando e analisando os resultados obtidos durante os dois semestres letivos. A partir das observações, é possível propor novas atividades e intervir quando há possibilidades.

Os dados analisados em campo, a partir das observações e intervenções, são discutidos periodicamente com os pesquisadores do projeto, objetivando desvelar concepções acerca das práticas inclusivas. Essas discussões são realizadas em reuniões pedagógicas, coordenadas por especialistas da área que participam do grupo. 


\section{RESULTADOS}

Desde o ano de 2006, o projeto desenvolvido no âmbito do Núcleo de Ensino proporcionou a realização de atividades formativas em mais de 50 escolas, com a concessão de 35 bolsas. As atividades desenvolvidas pelos estudantes de graduação, bolsistas dos projetos, proporcionam a reflexão e contato com o ambiente escolar. A partir das observações, os estudantes têm a oportunidade de verificar as dificuldades que envolvem o processo de inclusão nas instituições de ensino, para que, assim, possam procurar meios para superar os desafios impostos, juntamente com os professores em processo de formação.

Com o desenvolvimento dos projetos, verificamos que as intervenções e materiais desenvolvidos podem proporcionar ganhos para as escolas e para a prática pedagógica, pois a descoberta de possibilidades e as parcerias contribuem para que todos pensem em práticas que promovam a inclusão dos EPAEE. Conforme Mantoan (2002) é necessário que as escolas criem projetos de ensino que reconheçam e valorizem as diferenças, encerrado em uma proposta de escola para todos, com uma atuação pedagógica voltada para superar as barreiras impostas pela exclusão, reforçando a importância da viabilização de ambientes heterogêneos.

Nessa perspectiva, para a constituição de instituições de ensino inclusivas, o projeto desenvolvido, ao estabelecer parceria entre universidade e escola, viabiliza a formação de professores para que o ensino atenda às diferenças e as especificidades de cada estudante.

Diante disso, a formação inicial dos bolsistas e a formação continuada dos professores se torna significativa, pois a parceria mútua proporciona o diálogo sobre as práticas, troca de experiências e conhecimentos. Além de terem acesso a bibliografia que norteia a inclusão escolar e as práticas de ensino inclusivas, os estudantes bolsistas têm a oportunidade de vivenciar experiências escolares, que fortalecem a sua formação.

\section{DISCUSSÃO}

A formação inicial e continuada em uma abordagem CCS perpassa pela busca de novos conhecimentos e de novas estratégias de ensino que favoreçam a aprendizagem e participação de todos os estudantes.

No decorrer do desenvolvimento das atividades do projeto NE, os bolsistas são integrados ao contexto escolar e observam todos os resultados obtidos, analisando como se deu o trabalho, propondo atividades e intervindo quando há possibilidades. Com os resultados, os dados são utilizados para refletir com o grupo como melhorar os trabalhos em desenvolvimento, ocorrendo a espiral da aprendizagem, em um movimento de depuração e reflexão sobre as ações. Além disso, periodicamente é realizado um encontro com o coordenador/orientador e o grupo, para discutir os resultados obtidos e definir novas ações que se fizerem necessárias.

Almejando atingir os objetivos propostos, no decorrer da pesquisa, o bolsista busca desvelar concepções acerca das práticas inclusivas e as posturas necessárias para sua realização. A formação de estagiários dos cursos de graduação em Licenciaturas, participantes do projeto, é uma das metas do projeto, com a finalidade de garantir que a abordagem CCS seja incorporada, trazendo significado para a formação inicial e para o processo de inclusão de acordo com as necessidades do ambiente pesquisado.

Paralelamente, os bolsistas realizam estudos teóricos sobre as estratégias pedagógicas, os processos de formação, os marcos legais das políticas nacionais, estaduais e municipais, entre outros. Nos encontros do grupo de pesquisa API, dialogamos sobre os trabalhos realizados, sobre os resultados e dificuldades de maneira a favorecer uma troca de experiências para a melhoria das ações de cada estagiário. 


\section{CONCLUSÃO}

O eixo norteador do Programa Núcleo de Ensino é o desenvolvimento da competência do licenciando, estabelecendo uma relação direta com a escola e os docentes, com vistas a entender a ótica do ensino e a aprendizagem. Para isso, podem ser desenvolvidos programas, cursos, oficinas pedagógicas e de outras atividades.

O Grupo API tem proposto desde 2006 um projeto integrado à realidade das escolas, favorecendo o intercâmbio de experiências sobre um tema significativo para a Educação e para a política educacional do Brasil, que é a Educação Escolar Inclusiva. Nessa perspectiva, os licenciandos tem oportunidades ímpares para compreender o que é inclusão, vivenciando na prática os dilemas, desafios e estratégias inerentes ao trabalho pedagógico junto aos estudantes com deficiências e todos os outros estudantes, que fazem parte da escola para todos.

\section{REFERÊNCIAS}

BRASIL. Constituição (1988). Constituição da República Federativa do Brasil. Brasília, DF: Senado Federal, 1988.

BRASIL. Declaração Mundial sobre Educação para Todos: plano de ação para satisfazer as necessidades básicas de aprendizagem. UNESCO, Jomtiem/Tailândia, 1990.

BRASIL. Declaração de Salamanca e linha de ação sobre necessidades educativas especiais. Brasília: UNESCO, 1994.

BRASIL. Senado Federal. Lei de Diretrizes e Bases da Educação Nacional: no 9304/96. Brasília: 1996.

BRASIL: Ministério da Educação. Secretaria de Educação Especial. Política Nacional de Educação Especial na perspectiva da Educação Inclusiva. Brasília: MEC/SEESP, 2008.

MANTOAN, M. T. E. O desafio das diferenças nas escolas. Petrópolis: Editora Vozes, 2008.

MANTOAN, M. T. E. Ensinando à turma toda as diferenças na escola. Pátio revista pedagógica, ano V, n. 20, fev./abr. 2002, p. 18-23.

RICHARDSON, Roberto J. et al. Pesquisa social: métodos e técnicas. 3. ed. 14. reimpr. São Paulo: Atlas, 2012.

SCHLÜNZEN, E. T. M. Mudanças nas práticas pedagógicas do professor: criando um ambiente construcionista contextualizado e significativo para crianças com necessidades especiais físicas. 2000. 212 p. Tese (Doutorado em Educação: Currículo) - Pontifícia Universidade Católica de São Paulo, São Paulo, 2000. 